\title{
Cortical Plaque-Like Structures Identify Ribosome-Containing Domains in the Mauthner Cell Axon
}

\author{
Edward Koenig' ${ }^{1}$ and Rainer Martin ${ }^{2}$ \\ ${ }^{1}$ Department of Physiology, University at Buffalo School of Medicine, Buffalo, New York 14214, and 2Sektion \\ Elektronenmikroskopie, Universität Ulm, D-89069 Ulm, Germany
}

The hypothesis that ribosomes are present, but may have a restricted distribution, in the Mauthner $(\mathrm{M})$ axon was evaluated in isolated M-cell axoplasm after (1) staining with YOYO-1 and (2) inspection by electron spectroscopic imaging (ESI) of ribosomal RNA (rRNA) phosphorus $(P)$. Discrete periaxoplasmic plaques, identified by their ribonuclease-sensitive fluorescence, were located circumferentially at the surface boundary of isolated axoplasm and distributed longitudinally at random intervals. Conditions that destabilized plaques, and surface blotting of plaques onto a coverslip, revealed that fluorescent puncta were probably a significant source of plaque fluorescence. Fluorescent puncta were also distributed in a delimited volume of axoplasm, subjacent to the plaque. The notably higher density of F-actin in the latter region suggested that the actin cytoskeleton may govern the spatial distribution of puncta in subcortical axoplasm. Some fluorescent plaques were superficial to the cortical F-actin layer, whereas others formed inclusions within the F-actin layer; however, plaques did not appear to contain F-actin. Periaxoplasmic plaques were also identified in ordinary myelinated axons.

ESI, in which rRNA emits bright signals in the phusphorus $(P)$ spectral line against a low-contrast background, showed that isolated axoplasm contained characteristic $25 \mathrm{~nm} P$ signals, which were associated or in direct contact with a pleiomorphic structural matrix, located at the surface boundary. Polyribosomal $\mathrm{P}$ signals were also distributed in peripheral axoplasm below the matrix. The concept of a distinct polyribosomepopulated domain, distributed intermittently in the cortical zone of the axon is described. This domain is spatially defined by a plaque-like periaxoplasmic structural matrix, and a confluent volume of subcortical axoplasm integrated through an actin cytoskeleton.

Key words: ribosomes; YOYO-1; actin; axon; electron spectroscopic imaging; Mauthner neuron; goldfish
The mature axon is generally considered to be a metabolic compartment of the neuron that lacks an endogenous capacity to synthesize proteins. This prevailing dogma started with early ultrastructural studies, which notably yielded little evidence of ribosomes in vertebrate axons (Peters et al., 1970), and it was reinforced further when ribosomal RNA (rRNA) was not present in RNA extracts from squid giant axoplasm (Lasek et al., 1973). These early negative findings notwithstanding, ribosomes were reported later in proximal regions of vertebrate axons (see references in Koenig, 1989, 1991), and rRNA was subsequently extracted from squid axoplasm (Giuditta et al., 1980).

The demonstration of slow transport rate groups for proteins (Willard et al., 1974; Hoffman and Lasek, 1975) and an apparent lack of local machinery led by default to the conclusion that axoplasmic proteins were metabolically stable irrespective of axon length (Lasek and Hoffman, 1976). Nonetheless, if axoplasmic proteins have a limited half-life, as evidence suggests (Nixon, 1980; Koenig, 1991), then local synthesis is needed to maintain

\footnotetext{
Received Sept. 11, 1995; revised Nov. 15, 1995; accepted Nov. 20, 1995.

This work was supported in part by Grant BNS 90-10251 from the National Science Foundation to E.K. We thank the following people: Dr. Mark Terasaki, who suggested the use of YOYO-1; Dr. Sarah Finnegan for her technical assistance during the initial phase of this study; Dr. Robert Summers for his technical assistance with confocal microscopy; and Dr. Thaddeus Szezesny and Ms. Julie Lakatos for their help with photographic work. We also thank Dr. Robert Hard for his assistance with image processing of the ESI micrograph in Figure 10, and we thank him and Dr. Dennis Higgins for their critical comments.

Correspondence should be addressed to Dr. Edward Koenig, Department of Physiology, School of Medicine, University at Buffato, Buffalo, NY 14214.

Copyright $(C) 1996$ Society for Neuroscience $0270-6474 / 96 / 161400-12 \$ 05.00 / 0$
}

axoplasmic protein mass in a steady state (Koenig, 1984; $\Lambda$ lvarez and Torres, 1985).

Although there appears to be a local glial-axonal transfer of proteins in the squid giant axon (Lasek et al., 1974; Gainer et al., 1977; Lasek et al., 1977; Tytell and Lasek, 1984), a body of biochemical evidence also indicates that there is an endogenous protein-synthesizing machinery in several axon models studied (van Minnen, 1994). In the squid giant axon, elongation factors (Giuditta et al., 1977), tRNA, aminoacyl-tRNA synthetases (Lasek et al., 1973; Black and Lasek, 1977; Giuditta et al., 1977; Ingoglia et al., 1983), as well as rRNA (Giuditta et al., 1980) and a heterogeneous family of mRNAs (Giuditta et al., 1986; Perrone Capano et al., 1987), have been reported. $\beta$-Actin, $\beta$-tubulin (Kaplan et al., 1992), kinesin (Giorio et al., 1994), and neuronspecific enolase mRNAs (Chun et al., 1995) have now been shown to be constituents of this heterogeneous mRNA population. Finally, a riboprobe-encoding murine neurofilament protein crosshybridized with an endogenous mRNA in axoplasmic polyribosomes (Giuditta et al., 1991).

There is also supporting evidence of an endogenous machinery in vertebrate axons. For example, rRNA can be microextracted from isolated Mauthner (M)-cell axoplasm (Koenig, 1979), and neurofilament mRNA (i.e., neurofilament-L) has been demonstrated recently in axons of the rat hypothalamo-neurohypophyseal tract (Mohr and Richter, 1992). Furthermore, proteinsynthesizing activity has been probed in a number of axonal systems, which have included axons from the hypoglossal nerve of the rabbit (Tobias and Koenig, 1975), dorsal and ventral roots of the rat (Koenig, 1991), M-cell axons of the goldfish (Edström and 
Sjöstrand, 1969; Alvarez and Benech, 1983; Koenig, 1991), and goldfish retinal ganglion-cell axons regenerating in explant culture (Koenig and Adams, 1982; Koenig, 1989). In all of these cases, inhibitors of protein synthesis blocked incorporation of amino acids.

The apparent lack of ribosomes in M-cell axoplasm (Edström et al., 1969; Koenig, 1979; Alvarez and Benech, 1983), while being able to extract rRNA (Koenig, 1979), posed a vexing question: Where could ribosomes be located in this compartment? One possibility is that ribosomes may have a restricted distribution, which could be easily overlooked by casual inspection at the electron microscope (EM) level.

To identify potential domains that may contain ribosomes, we have isolated M-cell axoplasm and used YOYO-1, a high-affinity nucleic acid-binding fluorescent dye, to visualize potential RNAcontaining domains. Observations at the light microscope (LM) level then served to guide ultrastructural examination, using electron spectroscopic imaging (ESI) to map rRNA phosphorus (P) signals. ESI, which permits mapping of elements, was first used by Korn et al. (1983) to visualize ribosomes and to estimate rRNA P content. These techniques have provided structural evidence for the intermittent occurrence of specialized ribosome-containing cortical domains in myelinated axons of the goldfish.

\section{MATERIALS AND METHODS}

Isolation of $M$-cell axoplasm for light microscopic inspection. Common goldfish (4-5 inches; Ozark Fisheries, Stoutland, MO; Grassy Forks Fisheries, Martinsville, IN) were used. The goldfish was anesthetized by cooling in ice water, and all procedures with native tissues were performed in an ice bath. The isolated spinal cord and lower brain stem (Koenig, 1983) were suspended in a modified, gluconate-substituted, calcium-free Cortland salt solution $(\mathrm{Na} \mathrm{G} / \mathrm{C}$; in $\mathrm{mm}$ ): $132 \mathrm{Na}-$ gluconate, $5 \mathrm{NaCl}, 20 \mathrm{HEPES}, 10$ glucose, $3.5 \mathrm{MgSO}_{4}$, and $2 \mathrm{EGTA}$ $\mathrm{pH} 7.2$. Native axoplasm was pulled from tissue segments $(0.8-1 \mathrm{~cm})$ with a pair of no. 5 microtweezers in a $\mathrm{K}$-for-Na- and Na-for-Ksubstituted gluconate/Cortland salt solution $(\mathrm{K} \mathrm{G} / \mathrm{C})$. Except where noted otherwise, $30 \mathrm{~mm} \mathrm{Zn}$-acetate in $\mathrm{K} \mathrm{G} / \mathrm{C}$ was used to improve stabilization. Stabilization of ordinary myelinated axons was improved further by immersing tissue segments first in unbuffered $0.1 \mathrm{M} \mathrm{Zn-}$ acetate, $\mathrm{pH} 6.5$, for $20 \mathrm{~min}$ and pulling axoplasm in $20 \mathrm{~mm} \mathrm{Zn}$-acetate in $\mathrm{K} \mathrm{G} / \mathrm{C}, \mathrm{pH}$ 6.0. Isolated axoplasmic segments were attached with the aid of eyebrow hair tools to a no. 1 coverslip coated by evaporation of $1 \%$ 3-aminopropyltriethoxysilane (Polysciences, Warrington, PA) in ethanol.

Staining with YOYO-1, with or without rhodamine phalloidin. YOYO-1 iodide (491/509) (Molecular Probes, Eugene, OR) in K G/C 1:10,000 $(\mathrm{v} / \mathrm{v})$, was used to stain RNA-containing domains in native or fixed axoplasm. Native axoplasm was stained with YOYO 1 (30 min) during isolation in $\mathrm{K} \mathrm{G} / \mathrm{C}$, washed three times (5 min each) with $\mathrm{K} \mathrm{G} / \mathrm{C}$, and viewed in the latter solution after inversion of the coverslip over 0.5 - to 1-mm-thick SILASTIC elastomer (Dow Corning, Midland, MI) spacers of a perfusion chamber. $\mathrm{Zn}$-isolated axoplasm was fixed with $3.75 \%$ $p$-formaldehyde in $\mathrm{K} \mathrm{G} / \mathrm{C}$ medium for $15 \mathrm{~min}$, washed twice ( 10 min each) with $0.15 \mathrm{M}$ ammonium acetate and $10 \mathrm{~mm} \mathrm{Na}$-EDTA, and $5 \mathrm{~mm}$ dithiothreitol was added to a third wash to complex any residual $\mathrm{Zn}$. Axoplasm was then incubated with 1:10,000 YOYO-1 in $\mathrm{K} \mathrm{G} / \mathrm{C}$ for $30 \mathrm{~min}$ and washed twice ( $5 \mathrm{~min}$ each) with $\mathrm{K} \mathrm{G} / \mathrm{C}$, washed once for $5 \mathrm{~min}$ in 0.1 $\mathrm{M}$ ammonium acetate, and mounted on a slide with ELVANOL (Dow Corning).

In some experiments, $\mathrm{Zn}$-isolated axoplasm was double-stained with YOYO-1 and rhodamine-conjugated phalloidin (Molecular Probes) after fixation. After the third wash step after YOYO-1 staining ( $\mathrm{scc}$ above), axoplasm was incubated with $10 \mathrm{U} / \mathrm{ml}$ rhodamine-phalloidin in $1 \%$ dimethylsulfoxide in $\mathrm{K} \mathrm{G} / \mathrm{C}$ for $30 \mathrm{~min}$, washed, and mounted on a slide as described.

Ribonuclease (RNase) digestion of isolated M-cell axoplasm. After $p$-formaldehyde fixation of axoplasmic segments attached to a coverslip, the preparation was incubated in $0.4 \mathrm{mg}$ of $\mathrm{RNase} / \mathrm{ml}$ (Worthington Biochemical, Freehold, NJ) $\mathrm{K} \mathrm{G} / \mathrm{C}$ at $27^{\circ} \mathrm{C}$ for $45 \mathrm{~min}$, while matched control axoplasmic segments were incubated without RNase under the same conditions.

Fluorescence microscopy of YOYO-1-stained M-cell axoplasm. For routine fluorescence microscopy, specimens were examined in an Olympus BHS microscope with $\times 16$ [numerical aperture (N.A.), 0.4], $\times 40$ (N.A., 0.70 ), and $\times 100$ oil immersion (N.A., 1.25) objectives. Photomicrographs were taken on 400 ASA T-Max film (Kodak, Rochester, NY). The confocal microscope was a Bio-Rad MRC-1000 (Hercules, CA) with krypton-argon laser in combination with an upright Nikon Optiphot microscope with $\times 40$ (N.A., 1.3) and $\times 100$ (N.A., 1.4) objectives. Some black and white and some color images were printed by a Codonics dye-sublimation color printer (Codonics, Middleburg, $\mathrm{OH}$ ).

Preparations for ESI. Specimens prepared for ESI included either (1) M-cell axoplasm or (2) M-cell fibers (axon with myelin sheath) isolated in $30 \mathrm{~mm} \mathrm{Zn-K} \mathrm{G/C}$. Ten to twelve segments were collected, arranged in a bundle, and attached to a coated no. 1 coverslip at their ends. The specimens were then fixed with $2.5 \%$ glutaraldehyde in $0.1 \mathrm{M}$ sodium cacodylate, $\mathrm{pH} 7.2$, for $1 \mathrm{hr}$. Because tissue for elemental mapping by ESI could not be treated with heavy metals, unstable compact myelin lipids had to be removed from $\mathrm{M}$-cell fiber specimens before embedding. For this purpose, isolated axon fiber segments were suspended in Tricine $(\mathrm{pH}$ 5.0 , unbuffered; Sigma, St. Louis, MO) with $0.1 \%$ polyoxyethene 20 cetyl ether (Brij 58; Sigma) at $4^{\circ} \mathrm{C}$ until myelin had disrupted and dispersed $(\sim 0.5 \mathrm{hr})$. The specimen was washed once with the same solution and then fixed.

After fixation, specimens were washed in $0.15 \mathrm{M}$ ammonium acetate ( 3 times, $15 \mathrm{~min}$ each), dehydrated in an acetone series, equilibrated in propylene oxide, and embedded in Epon. The coverslip was removed by immersion in $49 \%$ hydrofluoric acid in an ice bath, and the Epon wafer was washed with water. The bundled specimen was cut out of the wafer, and the middle $5 \mathrm{~mm}$ portion was divided into $1 \mathrm{~mm}$ blocks for sectioning. Ultrathin sections (15-25 nm thick) were cut from selected blocks. They were collected on uncoated 700-mesh grids and examined in a Zeiss CEM 902 transmission microscope equipped with an integrated electron energy spectrometer (Carl Zeiss, Oberkochen, Germany) and an image analysis system from Kontron (Munich, Germany).

\section{RESULTS}

\section{YOYO-1 staining of periaxoplasmic plaques in isolated M-cell axoplasm}

Axoplasm was pulled out of tissue segments and then attached to a coverslip to obtain a global overview, unobstructed by the myelin sheath. In the process of pulling out axoplasm, however, a shear plane is created between axoplasm and the myelin sheath, which disrupts the membrane (Koenig, 1979). The outermost cortex, a zone that is defined by an F-actin layer present in most cells (Bray and White, 1988), may also be perturbed; however, its relative integrity can be evaluated after staining with rhodamine-phalloidin (see below). Biological variation in the adherence of myelin and mechanical properties of the M-cell fiber are factors that affect the ease with which axoplasm can be pulled out of its ensheathment.

YOYO-1 is a recently developed ultrasensitive fluorescent DNA/RNA dye that is virtually nonfluorescent until it forms a stable complex with nucleic acids (Glazer and Rye, 1992; Rye et al., 1993). Staining of isolated native axoplasm with YOYO-1 yielded fluorescent structures localized at the surface boundary, as illustrated in Figure 1. They generally were elongated, with a more intense fluorescent perimeter (Fig. $1 A, B, D$ ), and could be quite expansive in covering larger-circumferential surface arcas (Fig. $1 D)$. Frequently, discrete fluorescent puncta, which were distributed in peripheral axoplasm subjacent to surface boundary structures (Fig. 1C; see also below), were visible in the perimeter depending on perspective.

Figure 2 contains a gallery of micrographs that show a random sampling of axoplasmic surface boundary fluorescent structures stained after fixation. The lower magnifications provide a more global overview of the distribution and variations in structural 

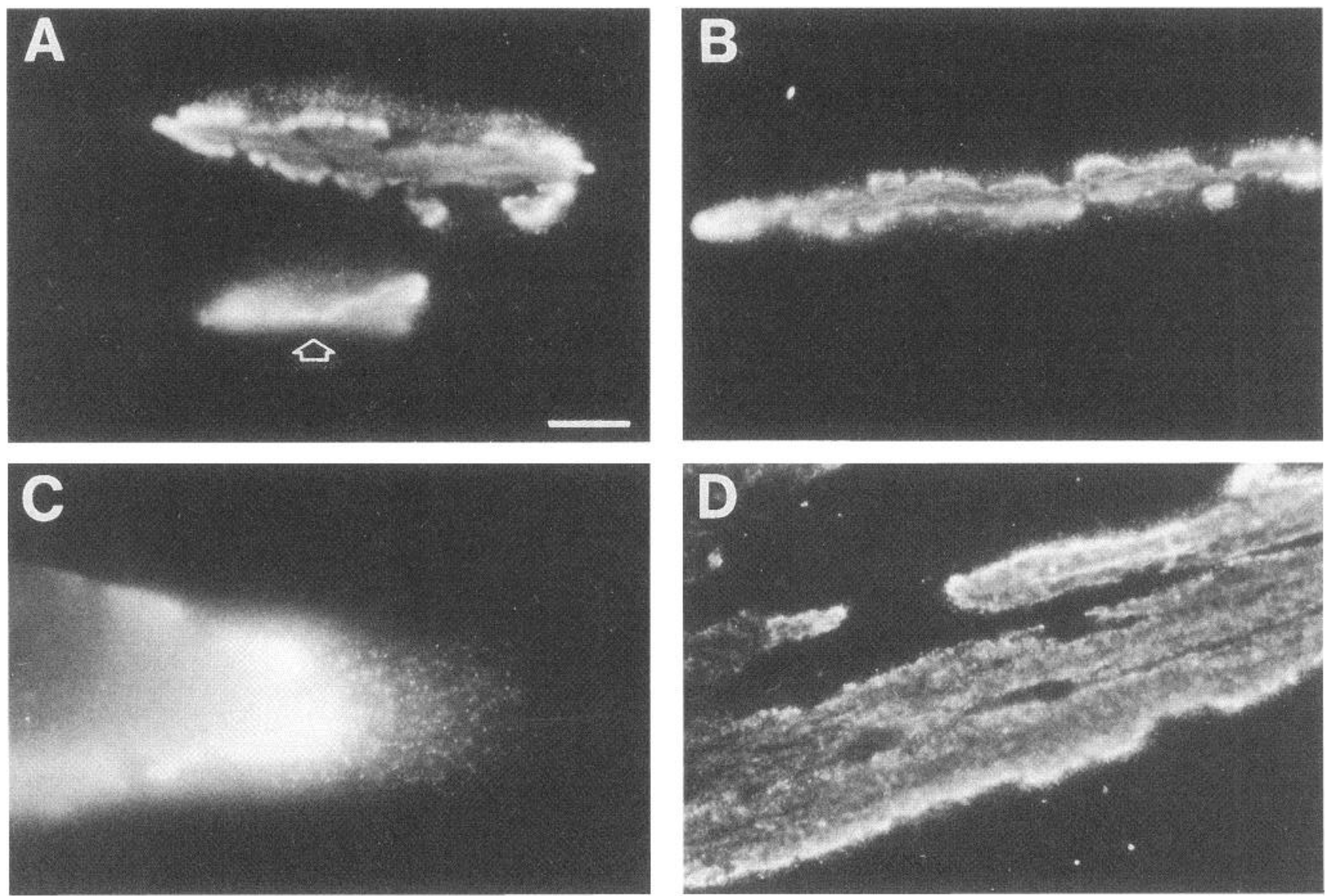

Figure 1. Selected en face views of fluorescent structures at the surface boundary of isolated native M-cell axoplasm after staining by YOYO-1. $A, B$, Two examples of elongated structural forms with intensely fluorescent perimeters associated with fluorescent puncta [lower structure in $A$ (arrow) is localized on the lateral aspect]. $C$, Fluorescent puncta are visible in peripheral axoplasm (ectoplasm) at one end of a surface boundary structure, and are focused in a plane below the fluorescent surface structure. $D$, An example of another common structural form, which is more expansive. An apparent fluorescent "fibrillar" organization can often be discerned in many surface boundary structures $(A, B$; see also Fig. $7 C 2)$. Scale bar, $10 \mu \mathrm{m}$.

forms. In these experiments, fixed axoplasmic segments were incubated in the absence or presence of RNase (see Materials and Methods). After RNase digestion, YOYO-1 fluorescence staining was either undetectable (Fig. $2 F$ ) or showed faint, residual traces of fluorescent surface boundary structures (Fig. 2G), which indicated that the fluorescent staining was attributable to RNA. Fluorescent surface structures similar to those in the M-cell axon were also present in axoplasm isolated from ordinary myelinated axons of the medulla and spinal cord (Fig. 2H,I).

Fluorescent surface structures in native (Fig. 1) and $p$-formaldehyde-fixed (Fig. 2) preparations appeared qualitatively similar in their YOYO-1-staining patterns. One difference in fixed axoplasm, however, was discrete punctate fluorescent signals localized in phase images of mitochondria. These signals were arranged in linear arrays of 1-4 per mitochondrion (not shown; but see Fig. 6) and were resistant to RNase digestion. In underexposed photomicrographs, the signals appear as a background "granularity" at low magnification (Fig. $2 F, G$ ). Their absence in the native state (Fig. 1) was consistent with the membraneimpermeant properties of YOYO-1 (Becker et al., 1994).

The superficial, circumferential localization of fluorescent structures at the surface boundary in isolated axoplasm was confirmed by confocal microscopy and is illustrated by the stereo pair in Figure 3. From inspection of Figures 1-3, surface boundary structures appear (1) to be distributed along the axon at intermittent and apparently random intervals, and (2) exhibit a wide variation in size, shape, and relative fluorescence intensity. Because of their thin, plaque-like appearance and their cortical localization, we will refer to them as "periaxoplasmic plaques."

Fluorescent plaques may exhibit structural correlates to varying degrees when viewed with differential interference contrast (DIC) or phase-contrast optics. Some plaques showed a close correspondence between fluorescent and phase structures (Fig. 4), whereas others had either no structural correlates or correlates outlining portions of their boundaries (not shown). This variability may reflect either some loss of surface integrity during isolation or a

Figure 2. A gallery of randomly selected examples of fluorescent surface boundary structures stained by YOYO-1 in M-cell axoplasm and in axoplasm from ordinary myelinated axons after $p$-formaldehyde fixation. $A-E 1$, Axoplasmic segments incubated 45 min at $27^{\circ} \mathrm{C}$ without RNase. Only fluorescent structures at the upper surface boundary were focused; surface boundary structures outside the plane of focus are blurred. The examples were photomicrographed as pairs: at low magnification $(A-E)$ to illustrate distribution of fluorescent structures and the wide range of structural forms, and at higher magnification $(A 1-E 1)$ to provide more detail. $F, G$, Axoplasmic segments that had been incubated with $0.4 \mathrm{mg} / \mathrm{ml} \mathrm{RNase}$ for $45 \mathrm{~min}$ at $27^{\circ} \mathrm{C}$ before 

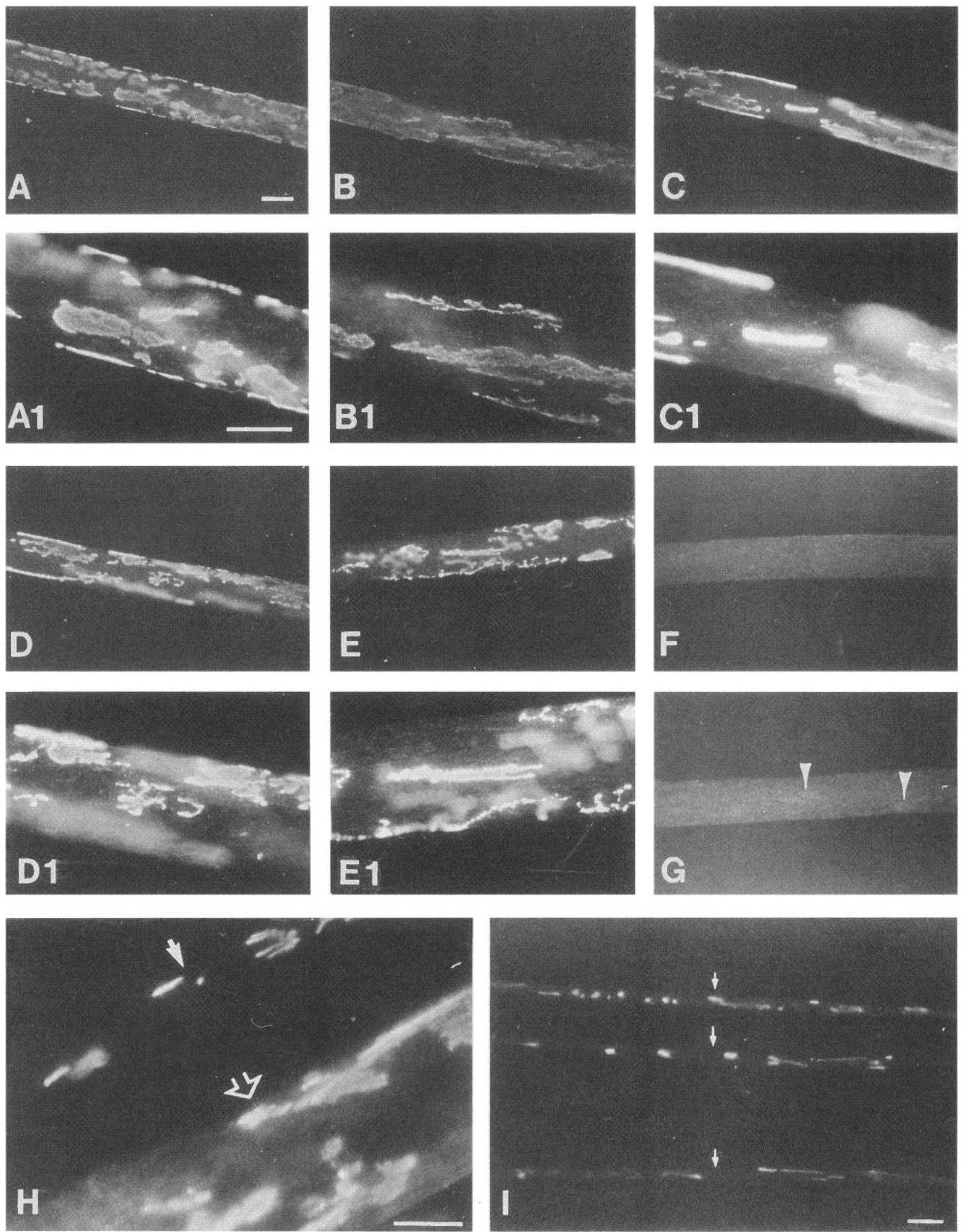

incubation with YOYO-1. YOYO-1 staining of surface boundary plaques after RNase digestion were either eliminated completely $(F)$ or showed only trace residual fluorescence remaining (arrowheads; $G$ ). Note that $F$ and $G$ were underexposed to reveal low levels of fluorescence, and that the fine granular background fluorescence was attributable to RNase-insensitive staining of mitochondria by YOYO-1 (see text; see also Figs. 3 and 5 ). $H$, YOYO-1 staining of axoplasm from an ordinary myelinated axon (closed arrow) compared with M-cell axoplasm (open arrow) isolated from the medulla. $I$, YOYO-1 staining of axoplasm from three ordinary myelinated axons (small arrows) isolated from the spinal cord. Scale bars: $A-G, 50 \mu \mathrm{m} ; A 1, E 1,75$ $\mu \mathrm{m} ; H, 30 \mu \mathrm{m} ; I, 50 \mu \mathrm{m}$. 


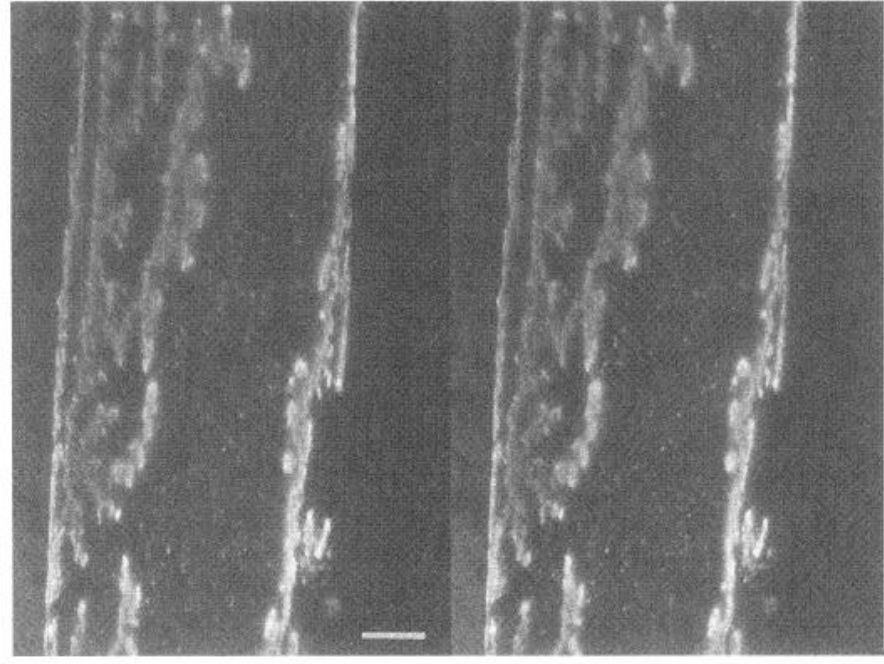

Figure 3. A stereo pair, which shows a three-dimensional rendering of a surface boundary structure stained with YOYO-1 after fixation and illustrating the latter's superficial circumferential localization, plaque-like appearance. The stereo view is from the vantage point of the upper surface of the axon. Each member of the stereo pair was obtained in a confocal microscope by maximum projection of 10 optical sections, $\sim 0.7 \mu \mathrm{m}$ thick, at $1 \mu \mathrm{m}$ intervals, with 0 and +1 pixel offset. Background punctate signals represent staining of mitochondria by YOYO-1 (see also Fig. 5). Scale bar, $10 \mu \mathrm{m}$.

variable extent to which plaques may be structurally integrated (i.e., buried) in the F-actin layer (see below).

\section{Fluorescent puncta in plaques and in associated subcortical axoplasm}

Fluorescent puncta (see above) may represent correlates of polyribosomal $\mathrm{P}$ signals visualized by ESI (see below). Two sets of observations suggest that plaques may contain puncta. First, on close inspection some plaques appear to exhibit an intrinsic fluorescent "fibrillar" organization (Figs. 1, 2, 7C2). Under conditions that destabilize plaques during isolation of axoplasm, a fibrillarlike organization is replaced by dispersed fluorescent puncta (not shown), at which time some fluorescent puncta may even become suspended in the bathing medium. Such observations suggest that a fibrillar organization in some plaques may represent close packing and/or overlap of fluorescent puncta.

Second, superficially localized fluorescent puncta can be transferred to a coverslip when the surface of axoplasm is blotted. An example is shown in Figure $5 A$, in which isolated axoplasm was pressed onto a coverslip surface with an eyebrow hair tool, peeled off, and reattached nearby. Blotted fluorescent components are left adsorbed to the coverslip surface, which may include many puncta-like aggregates (Fig. $5 B$ ). After blotting, a fluorescent residue is retained in axoplasm (see Fig. 5A), which indicates that only superficially localized fluorescent components are transferred.

As noted previously, fluorescent puncta are also distributed in peripheral axoplasm and may be visible at the perimeter of plaques in en face views at higher magnification (Fig. 1). Optical sectioning by confocal microscopy indicated that the puncta were confined to a delimited volume of axoplasm contiguous to the overlying plaque (Fig. 6). Figure 6 also shows multiple YOYO-1fluorescent signals in mitochondria, which are widely dispersed in regions outside of the delimited volume of axoplasm.

When plaques are viewed in longitudinal profile, fluorescent puncta in subcortical axoplasm range from very sparse to abundant in occurrence, and their distribution and density beneath the plaque can also vary greatly. Figure $7 A 1-A 3$ shows an example of axoplasm after double staining with YOYO-1 and rhodamine-phalloidin (see below), in which puncta distribution is markedly asymmetric and nonuniform in density. Also, in this case it is noteworthy that whereas puncta density falls off very sharply in a radial direction, a few puncta are scattered well within the central region of the axon (Fig. 7A3). Irrespective of the character and variations in puncta distribution and density, the latter are clearly related spatially to the localization of cortical plaque structures. The plaques, therefore, appear to define a domain in the cortical and subcortical zone of the M-cell axon in which puncta are localized.

\section{Relationship of periaxoplasmic plaques and axoplasmic fluorescent puncta to F-actin}

Plaques are located at the surface boundary of isolated axoplasm, which is a zone that contains a cortical F-actin layer (see below) that lies subjacent to the neuronal plasma membrane (LeBeux and Willemot, 1975; Hirokawa, 1982) (for review, see Bray and White, 1988). This localization raises questions regarding the relationship of plaques to the actin cytoskeleton and whether plaques contain actin. To probe these questions, plaques were labeled with YOYO-1, and F-actin was labeled with rhodamine-phalloidin in fixed axoplasm and examined by confocal microscopy (Fig. 7).

En face views of the axoplasmic surface after staining with rhodamine-phalloidin reveal a dense F-actin meshwork (Fig. $7 B 1, C 1$ ). In areas where fluorescent plaques are localized (Fig. $7 B 2, C 2)$, the cortical actin cytoskeleton may or may not exhibit structural alterations. For example, the F-actin meshwork (Fig. 7B1) underlying plaques (Fig. 7B2) appears either similar or reduced in density compared with the meshwork outside the plaque area. In Figure $7 C 1$, there are frank vacant spaces in the F-actin layer, which are bounded by a rim of condensed F-actin. The spaces are occupied by a fluorescent plaque structure (Fig. $7 C 3$ ). In an optically sectioned longitudinal profile (Fig. 7A1-A3), discontinuities in the F-actin layer are also apparent, which appear filled by a green fluorescence from plaque components. Merged YOYO-1 and rhodamine-phalloidin fluorescence images in Figure 7A3-C3 show local regions of overlap (i.e., yellow fluorescence), especially along portions of plaque borders. This indicates a close structural relationship of the two sources of fluorescence. Nevertheless, where there are vacant spaces in the F-actin layer (Fig. 7C3), rhodamine fluorescence is not evident. This suggests that F-actin is not a significant component of the plaque structural makeup.

When a plaque is viewed in longitudinal profile (Fig. 7A1-A3), phalloidin fluorescence (Fig. 7A1) is augmented in a region of axoplasm, which corresponds to the distribution of fluorescent puncta. The yellow fluorescence, signifying pixel overlap of the two fluorescence sources (Fig. 7A3), is especially intense at one pole of the plaque, where both F-actin and fluorescent puncta are in highest density. The increased density of F-actin in the axoplasmic zone subjacent to the plaque suggests that the distribution of fluorescent puncta may be governed by an actin-filament network that is also linked to cortical layer structures.

\section{ESI of RNA P in isolated M-cell axoplasm or myelin lipid-depleted fibers}

ESI provides a method for mapping P-rich structures such as ribosomes at an ultrastructural level. In ESI, elastically scattered electrons are filtered, and images are formed by electrons inelastically scattered with an energy loss characteristic of a specific 

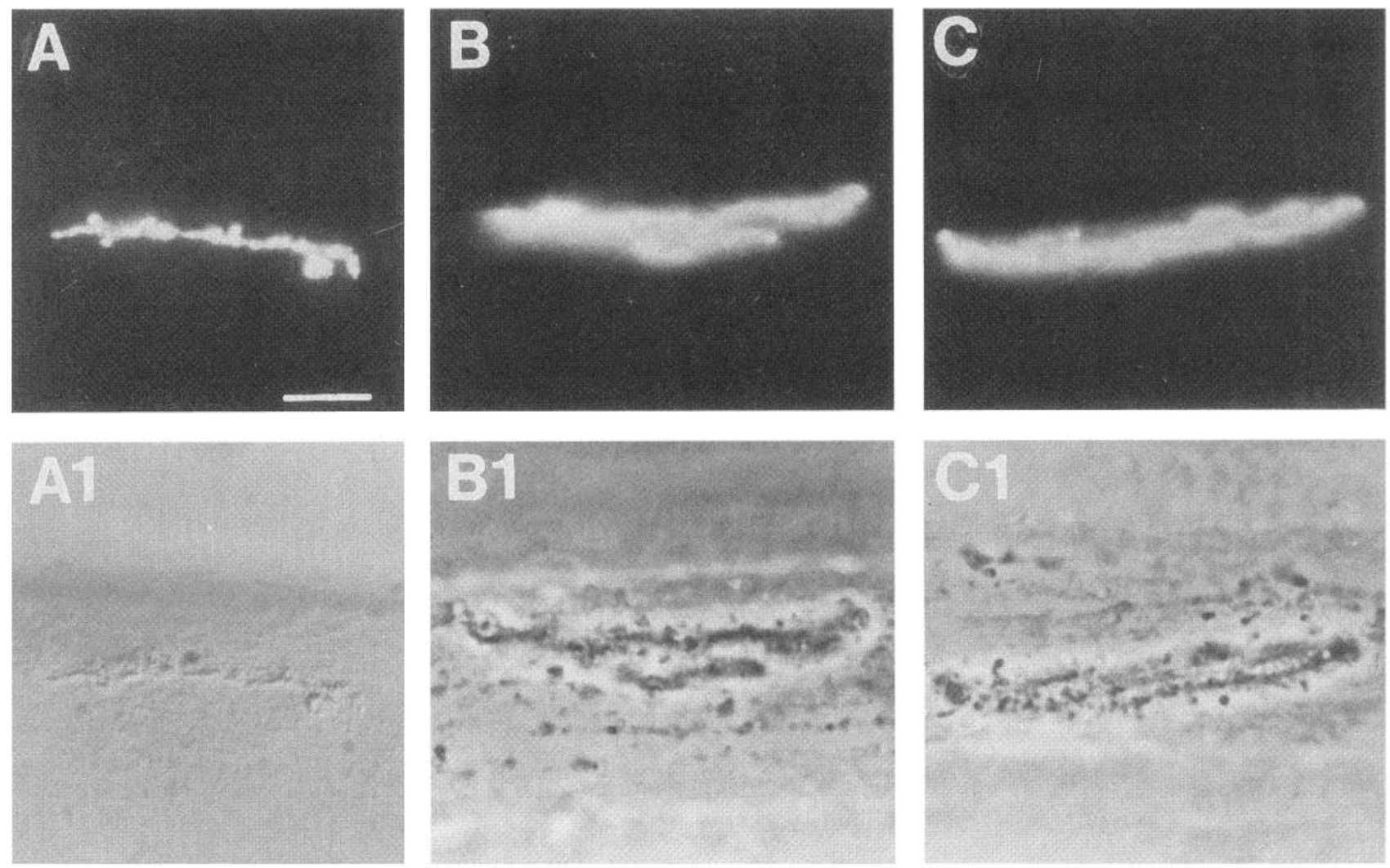

Figure 4. Examples of fluorescent and nonfluorescent structural correlates. $A-C$, Fluorescent periaxoplasmic plaques in isolated, unfixed, native axoplasm. Corresponding nonfluorescent structural correlates, as seen with DIC $(A 1)$ and with phase-contrast optics $(B 1, C 1)$. Note that the structures lie superficial to the surface boundary of isolated axoplasm. Scale bar, $10 \mu \mathrm{m}$.

element within the specimen. Ultrathin sections are a prerequisite to limit inelastic electron scattering to one event (Ottensmeyer, 1986). Whereas the estimated lower limit of sensitivity is $30-50$ clustered P atoms (Ottensmeyer, 1986), eukaryotic ribosomes contain several thousand nucleotides and yield a spherical signal of $\sim 25 \mathrm{~nm}$. The $L_{2,3}$ ionization threshold for the P-absorption edge is $\Delta E=132 \mathrm{eV}$. Paired maps are routinely obtained in the energy-loss bandwidths above (i.e., $\Delta E=150 \pm 10 \mathrm{eV}$ ) and below (i.e., $\Delta E=110 \pm 10 \mathrm{eV}$ ) the P-absorption edge (Ottensmeyer and Andrew, 1980). Above the absorption edge, structural entities with abundant $\mathrm{P}$ exhibit an augmented specific brightness in a low contrast and dark field. Below the absorption edge, there are no specific $\mathrm{P}$ signals, and images are dark and of low contrast.

The exclusion of myelin from specimens is a prerequisite for inspection by ESI because of the structural instability of myelin lipids in the absence of osmium fixation. For this reason, either isolated M-cell axoplasm or isolated myelin lipid-depleted axon fibers (see Materials and Methods) were used for ESI analysis and mapping. As noted previously, there are variable shearing effects when axoplasm is pulled out of its myelin sheath that perturb the interface between the axon and myelin sheath; therefore, an axolemma is generally not visible.

Figure 8 contains a photomontage of a putative periaxoplasmic plaque in longitudinal profile, extending between bars of a grid hole and mapped at an energy loss of $\Delta E=150 \mathrm{eV}$. It appears to be composed of a nondescript matrix that has no intrinsic $\mathrm{P}$ signal, as indicated by its dark substance (see below). As revealed in Figures 8-10, many bright single and clustered $\mathrm{P}$ signals characteristic of ribosomes are associated with matrix com- ponents. Ribosome-containing domains were imaged above (Figs. $8 A, B, D, E, 9 A, 10,11 B, C$ ) and below (Figs. $8 C, 9 B, 11 D)$ the energyloss $\mathrm{P}$-absorption edge. The disappearance of bright signals, when ESI was in the energy-loss bandwidth below the P-absorption edge, indicates that the signals were attributable to P (Ottensmeyer and Andrew, 1980; Martin et al., 1993).

Polyribosomal P signals were not limited only to plaque matrix components at the surface boundary. They were also distributed in subcortical axoplasm, as indicated in Figures 8-10, including deeper portions (e.g., up to $4 \mu \mathrm{m}$ ) that were cropped in Figure 8 . Appropriately placed tangential sections in the subcortical axoplasmic domains of isolated myelin-depleted fibers also yielded multiple polyribosomal P signals (not shown). These observations were consistent with the distribution of fluorescent puncta after staining by YOYO-1 in the same subcortical zone of axoplasm (Figs. 1, 5, 7A2) and suggested, therefore, that puncta may be fluorescent correlates of polyribosomes.

In an extensive survey of deeper regions of M-cell axoplasm (i.e., central domain), ribosomal $\mathrm{P}$ signals were not detected in ESI. Nevertheless, it is likely, judging from examples such as that illustrated in Figure $7 A 3$, that there are probably instances in which ribosomes may be sparsely scattered below the cortical/subcortical zone. Finally, ribosomal P signals in ESI were not detected in axoplasm that had been digested with RNase before embedding.

\section{Plaque matrix and its relationship to ribosomal P signals}

Low-contrast images of plaque matrix in ESI provide limited ultrastructural information, and further analysis using conven- 

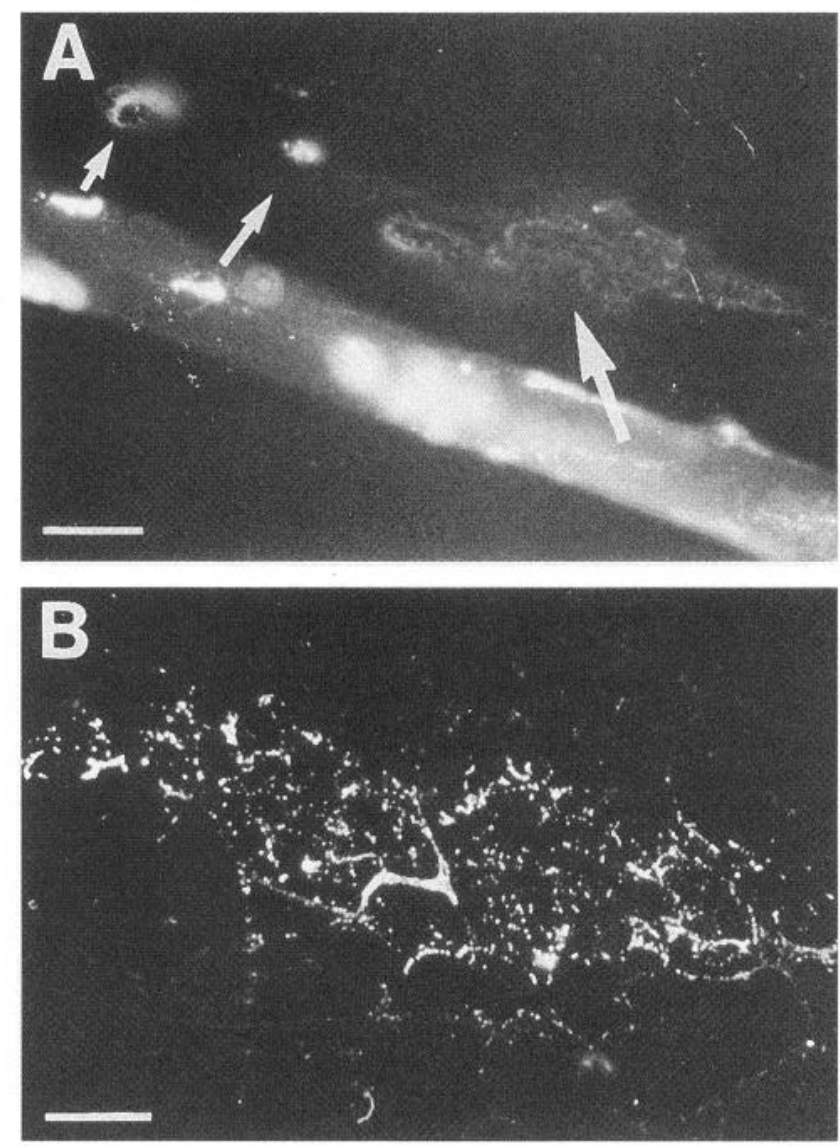

Figure 5. An example that shows that fluorescent components of periaxoplasmic plaques can be transferred to a coverslip surface by blotting. $A$, A segment of isolated native M-cell axoplasm stained by YOYO-1 was attached to the surface of a coverslip, lifted off, and reattached nearby, causing an incomplete transfer of superficial plaque components. Arrows indicate sources and corresponding blotted products. $B$, A blot of a periaxoplasmic plaque at high magnification, showing that fluorescent puncta can be transferred. Scale bars: $A, 50 \mu \mathrm{m} ; B, 10 \mu \mathrm{m}$.

tional EM methods is needed; nevertheless, plaque matrix structures appear nonuniform in density and highly irregular in structural architecture. Thus, in the latter respect, plaque matrix may appear organized, as lamina (Fig. $8 A 1-A 3, E$ ), or fenestrated structures (Figs. $8 A 1, B, C, 9,10$, arrows). Matrix also appears fragmentary, and such unorganized structures were quite prevalent and ubiquitous at the surface boundary (Figs. 8, 10). Fragmentary matrix was seen occasionally in axoplasm (Fig. 8A1,B, arrowheads). In summary, plaque structures appear as longitudinally oriented, pleiomorphic, and planar matrix, which may be layered, fenestrated, or fragmentary in their appearance.

Among plaque structures, polyribosomal $\mathrm{P}$ signals are associated with matrix components. Even within apparent spaces of matrix structures (Figs. $8 A 1-A 3,9 A$ ), inspection at higher magnification (Fig. $8 E$ ) indicates that most of the $\mathrm{P}$ signals are coapted or in direct contact with matrix substance (Figs. 9, 10). The prevalence of ribosomal $\mathrm{P}$ signals in direct contact with plaque matrix components suggests that the relationship between the two is not adventitious and likely is important for reasons that are presently unknown. These findings based on ESI suggest that matrix structures with associated ribosomal $\mathrm{P}$ signals are ultrastructural correlates of periaxoplasmic plaques stained by YOYO-1.

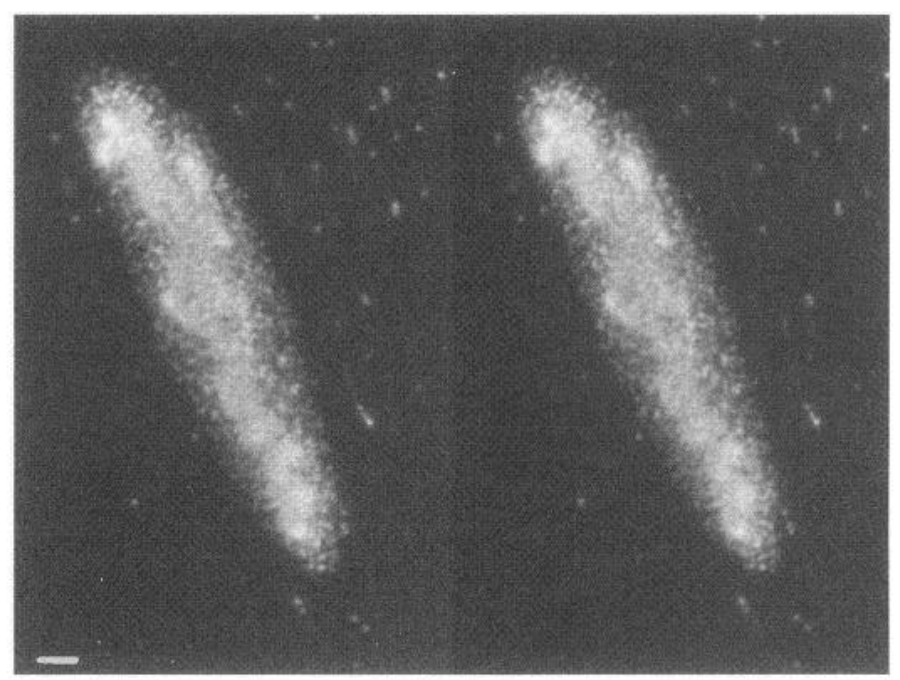

Figure 6. A stereo pair showing a three-dimensional rendering of a small periaxoplasmic plaque stained with YOYO-1 after fixation. Fluorescent puncta are distributed in a circumscribed volume of peripheral axoplasm (ectoplasm) subjacent to the plaque, and as viewed from a surface vantage point. Note that the distributional density of puncta appears relatively uniform, and that the volume boundary is roughly confluent with that of the plaque. Also present and widely dispersed in outlying regions surrounding the plaque domain are multiple (usually 1-4) YOYO-1fluorescent signals in linear arrays located in mitochondria. Each member of the stereo pair was obtained in a confocal microscope by maximum projection of 12 optical sections, $\sim 0.7 \mu \mathrm{m}$ thick, at $0.5 \mu \mathrm{m}$ intervals, with 0 and +1 pixel offset. Scale bar, $2 \mu \mathrm{m}$.

\section{DISCUSSION}

YOYO-1, a highly sensitive RNA/DNA-binding fluorescent dye, was used to evaluate whether there are restricted RNA-containing domains in isolated M-cell axoplasm. Fluorescence microscopy provided a basis for further ultrastructural analysis using ESI. ESI is a highly reliable method for visualizing rRNA P signals (Korn, 1983; Martin et al., 1989, 1993), and it removes potential ambiguity normally associated with the identification of ribosomal particles by conventional electron microscopy.

Inspection of isolated axoplasm after staining with YOYO-1 revealed novel, plaque-like structures located at the surface boundary, corresponding to the cortical actin layer. Fluorescence staining by YOYO-1 was sensitive to RNase digestion, which indicated that RNA was associated with the plaques. Thus, fluorescence staining of RNA highlighted a delimited, local domain shown to be structurally distinct from that of the cortical F-actin layer by phase-contrast or DIC microscopy, and by double staining with YOYO-1 and rhodamine-phalloidin. Fluorescent plaque structures were highly pleiomorphic in their shapes and staining features, and they were distributed at intermittent and apparently random intervals along the M-cell axon. They were also present with similar characteristics in axoplasm isolated from ordinary myelinated axons. Because of their circumferential localization and their planar appearance, they were named periaxoplasmic plaques and, to our knowledge, have not been described previously.

Confocal microscopy indicated that the plaque also appeared to mark the location of a delimited volume of peripheral axoplasm within which fluorescent puncta were distributed. The en face shape of this volume was approximately confluent with the overlying plaque structure, as defined by the fluorescence distribution of the latter. Plaques also appeared to contain fluorescent puncta because coverslip blots of surface plaque components contained 


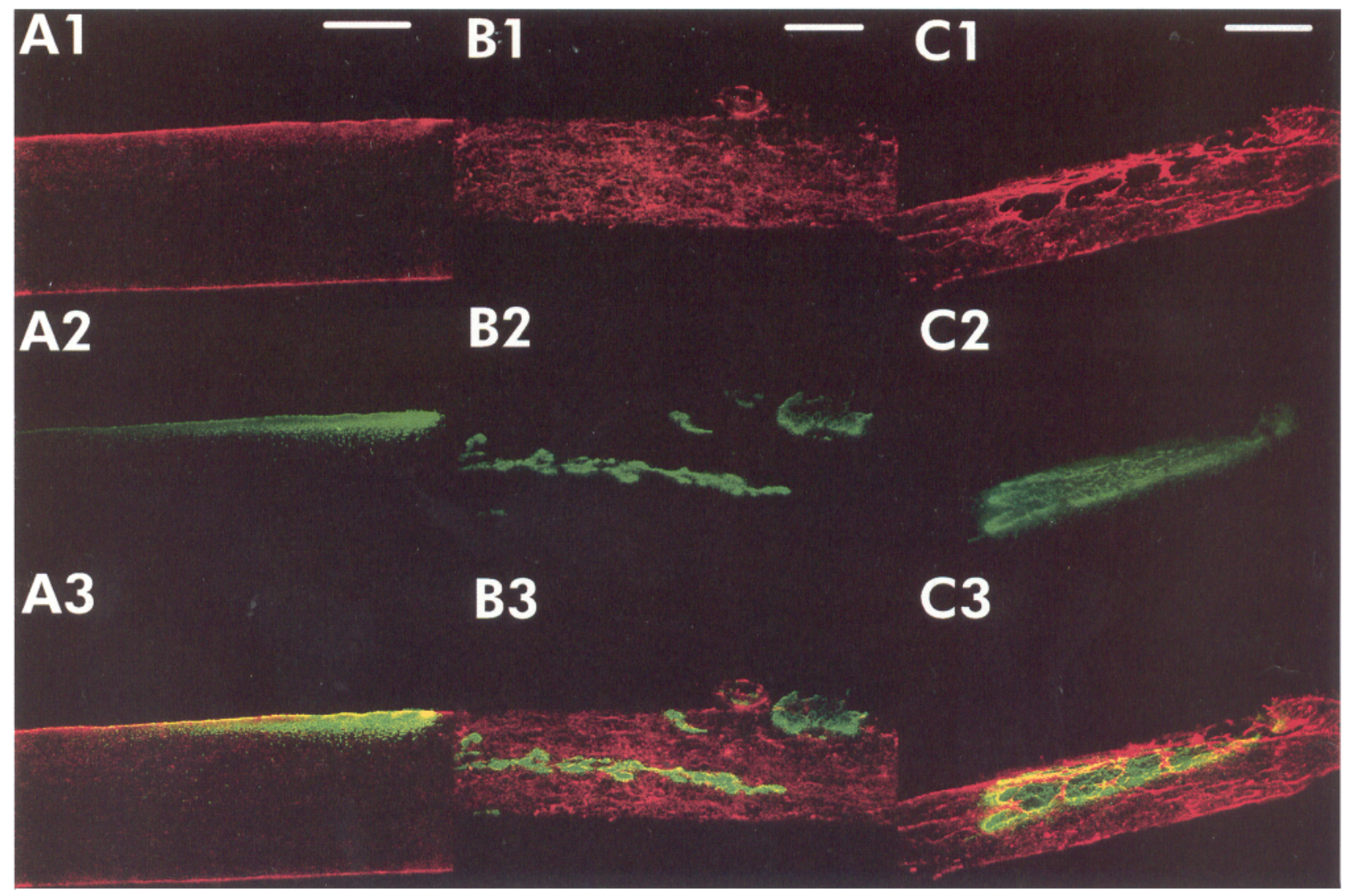

Figure 7. Relationship between periaxoplasmic plaques and the cortical actin cytoskeleton, as revealed by confocal microscopy after double labeling of periaxoplasmic plaques with YOYO-1 and F-actin with rhodamine phalloidin of $p$-formaldehyde-fixed M-cell axoplasm (see Materials and Methods). $A 1-C 1$, The cortical actin layer stained with rhodamine phalloidin. $A 2-C 2$, Periaxoplasmic plaques stained with YOYO-1. In $A 1-A 3$, the axon segment is shown in longitudinal profile; in $B 1-B 3$ and $C 1-C 3$, plaques are shown in en face views. $B 1-B 3$, The actin cytoskeletal meshwork appears intact under the elongated medial plaque, but appears thinned out or less dense under the rectangular plaque near the lateral edge. $C 1$, Prominent vacant spaces are present in the cortical F-actin layer, which are bounded by dense F-actin rims. $C 2, C 3$, A plaque is situated in the vacant spaces of the actin layer. $A 2$, $A 3$, YOYO-1 fluorescence of a plaque viewed in longitudinal profile also appears in a discontinuity of the actin layer (A1). Whereas fluorescent puncta $(A 2, A 3)$ have a polarized, nonuniform distributional density in peripheral axoplasm, some puncta are also scattered deep in the central domain of the axon. Note the variable higher density of F-actin in peripheral axoplasm $(A 1)$, which correlates with a correspondingly higher density of fluorescent puncta $(A 2, A 3)$. Scale bars: $A 1-A 3,10 \mu \mathrm{m} ; B 1-B 3,25 \mu \mathrm{m} ; C 1-C 3,33 \mu \mathrm{m}$

puncta, and the apparent fluorescent fibrillar organization of some plaques could be destabilized, which caused a dispersed puncta distribution. It appears, therefore, that the periaxoplasmic plaque, in conjunction with its subcortical axoplasmic volume of fluorescent puncta, identifies an RNA-containing local domain in the axon. Based on ESI mapping in these same regions (see below), it is likely that fluorescent puncta represent light microscopic correlates of polyribosomal P signals, although this has not been demonstrated directly.

Periaxoplasmic plaques were closely associated with the cortical F-actin layer, as indicated by double labeling of plaques and the actin cytoskeleton. Whereas some plaques seemed to lie superficial to the F-actin layer, as indicated by their elevated structural correlates in DIC or phase-contrast microscopy (Fig. 4) and as judged by an unaltered, underlying meshwork density (Fig. 7B1), others showed varying degrees of inclusion in the cortical F-actin layer, as indicated either by plaques overlying a sparser cytoskeletal meshwork (Fig. 7BI) or by their occupation of vacant spaces in the actin layer (Fig. 7C1). Periaxoplasmic plaques, however, did not exhibit detectable rhodamine-phalloidin fluorescence, which indicated that $\mathrm{F}$-actin was not a major constituent. Even where fluorescent puncta were distributed in axoplasm subjacent to a plaque (Fig. 7A2), a rhodamine-phalloidin fluorescence intensity higher than that in surrounding axoplasm indicated that an actin cytoskeleton codistributed with puncta (Fig. 7A1-A3).

We used ESI to identify and map rRNA $P$ in ultrathin, unstained sections of isolated M-cell axoplasm and myelin lipiddepleted fibers. Typical ribosomal $\mathrm{P}$ signals were associated with plaque matrix structures, and polysomal $\mathrm{P}$ signals were also distributed in subjacent axoplasm. These are similar domains where fluorescent puncta are seen at the LM level. We suggest, therefore, that fluorescent puncta may be correlates of polysomal $\mathrm{P}$ signals. Moreover, the codistribution of axoplasmic fluorescent puncta and F-actin, as seen in longitudinal profile by confocal microscopy, suggests that an actin cytoskeleton may provide structural scaffolding for polyribosomes in subcortical axoplasm. Thus, F-actin may spatially link the axoplasmic polyribosomal distribution with the plaque distribution.

In the cortical plane, where plaque matrix structures were located, ribosomal $\mathrm{P}$ signals appeared to bear a special relationship to the matrix substance, in that they either were coapted to or were in very close contact with organized (Fig. $8 A 1, E$ ) and fragmentary matrix (Fig. $8 A 1, D, E$ ) components. Discernible ribosomal $\mathrm{P}$ signals were also associated with fragmentary matrix in 

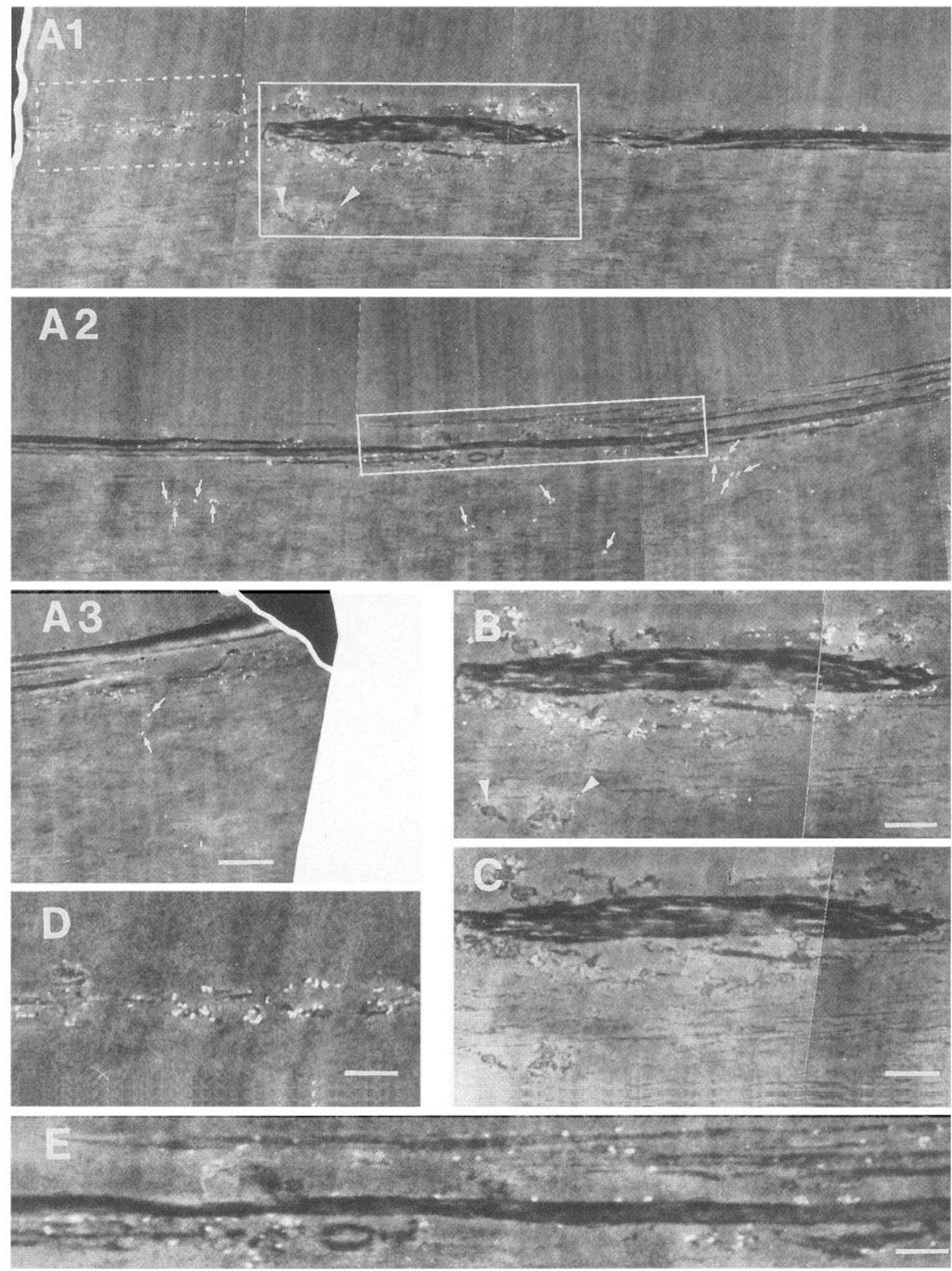

Figure 8. Portions of a putative periaxoplasmic plaque at the surface boundary of isolated axoplasm in longitudinal profile, and subjacent axoplasm, as mapped by ESI $(\Delta E=150 \mathrm{eV})$. $A 1-A 3$, For purposes of presentation, the plaque domain extending between bars of a grid hole has been divided into three consecutive segments, in which about half of the axoplasmic portion has been cropped. The plaque substance shows no intrinsic P signal and is composed of a nondescript matrix. The matrix varies in density and is structurally pleiomorphic, such that structures appear lamina-like, fenestrated, and fragmentary. Two matrix fragments (arrowheads) are in subcortical axoplasm (also shown at higher magnification in $B$ ). Bright ribosomal P signals are distributed along laminar and fenestrated matrix components, within apparent interlaminar spaces (see enlargement in $E$ ), associated with fragmentary 

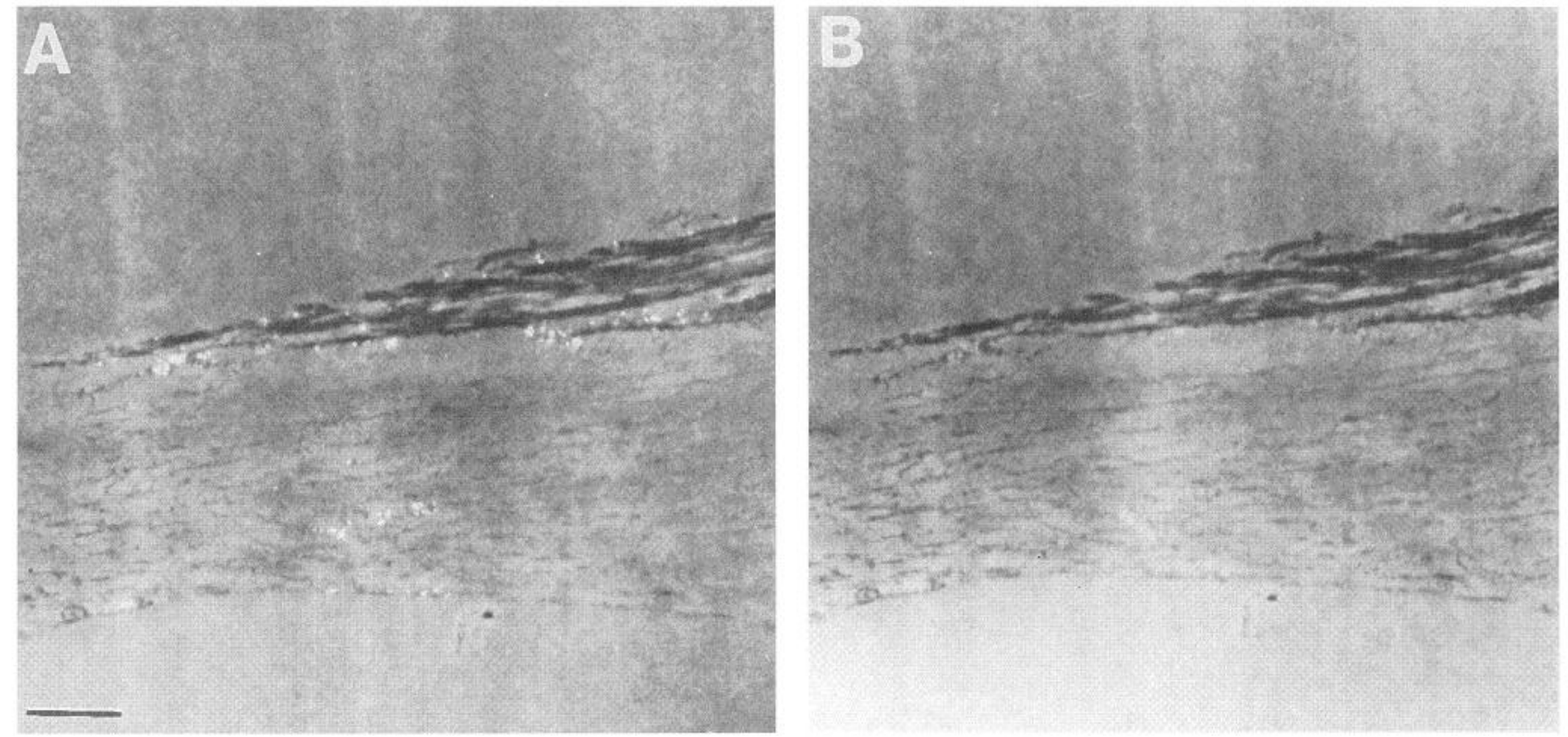

Figure 9. A portion of a putative periaxoplasmic plaque in a grazing section of isolated axoplasm, cut tangentially and mapped by ESI. The plaque matrix is both lamina-like and fenestrated in its structural architecture. $A$, Polyribosome-like P signals, mapped by ESI above the P-absorption edge ( $\Delta E=150$ $\mathrm{eV}$ ), are associated with fragmentary matrix, within interlaminar spaces, and in axoplasm. $B$, Ribosome P signals disappear when mapped by ESI below the P-absorption edge $(\Delta E=110 \mathrm{eV})$. Scale bar, $0.44 \mu \mathrm{m}$ (primary magnification, $22,500 \times$ ).

axoplasm (Fig. 8A,B); however, this was generally not prevalent. Nonetheless, further study is needed to evaluate this question because matrix fragments may be too small, out of the plane of section, or not distinguished from other cytoskeletal components in axoplasm because of low contrast. Although the high incidence of direct contact between ribosomes and plaque matrix suggests a relationship of some importance, its significance is presently unknown-but a function is suggested below. In any case, the identification of ribosomal $\mathrm{P}$ signals associated with plaque domains in the M-cell axon provides a structural basis for biochemical evidence of rRNA (Koenig, 1979).

Although it seems that the plaque matrix specifies a specialized ribosome-populated domain, the actin cytoskeleton probably plays important multiple roles in spatially defining/regulating this domain. Actin has multiple myosin motors (for review, see Cheney and Mooseker, 1992), and its assembly and disassembly are highly regulated in the cell (for review, see Stossel, 1993). There is considerable evidence that the actin cytoskeleton has an important spatial relationship to translational machinery in other cells (for review, see Hesketh and Pryme, 1991). Elongation factor $1 \alpha$ is also an actinbinding protein (Yang et al., 1990), the activity of which may be modulated by actin (Edmonds, 1993; Edmonds et al., 1995). Evidence in other cells also shows that ribosomes (Lenk et al., 1977; Ramaekers et al., 1983; Singer et al., 1989), mRNAs (Jeffery, 1982; Ornelles et al., 1986; Singer et al., 1989; Hoock et al., 1991; Taneja et al., 1992), and some initiation/elongation factors (Howe et al., 1984;
Yang et al., 1990; Shestakova et al., 1993; Edmonds et al., 1995) are associated with the actin cytoskeleton. Moreover, disruption of actin filaments by cytochalasin D releases mRNA and inhibits protein synthesis (Ornelles et al., 1986; Aggeler and Seely, 1990).

The cortical localization of ribosomal plaque domains in the axon may also be of importance for reasons in addition to the presence of an F-actin layer. For example, potential membranelinked signal transduction pathways, involving second messengers such as $\mathrm{Ca}^{2+}$ and/or cAMP, could regulate translational activity (see also Ryazanov et al., 1991). It is also possible that potential spatial and/or structural dynamics of the plaque domain may be subject to regulation. For any of these reasons, close proximity to the plasma membrane may be a prerequisite.

The presence of periaxoplasmic plaques appears ubiquitous among myelinated axons in the goldfish. Nonetheless, an intermittent, random distribution of ribosome-containing plaque domains located within a shallow cortical/subcortical zone makes it less likely that ribosomes would be detected by casual inspection at the EM level. A relatively low spatial frequency of distribution could provide an explanation for the inability to detect ribosomes previously in randomly selected thin sections of the M-cell axon (Edström et al., 1969; Koenig, 1979; Alvarez and Benech, 1983). A low spatial frequency notwithstanding, it should be possible to identify plaque domains by conventional electron microscopy.

Figure 11 is a diagram of a simple model of a periaxoplasmic plaque domain. The latter is depicted as a discrete, circumscribed

$\leftarrow$

matrix (area demarcated by broken lines and enlarged in $D$ ), and in subjacent axoplasm. Although the section thickness is less than that of a single ribosome, many P signals associated with matrix components and in subjacent axoplasm (small arrows) appear in polyribosome-like clusters. $B$, The fenestrated structural subdomain demarcated by an unbroken line in $A 1$ is shown at a higher magnification and mapped by ESI above the P-absorption edge $(\Delta E=150 \mathrm{eV}) . C$, The same structural subdomain as in $B$ mapped by ESI below the P-absorption edge $(\Delta E=110 \mathrm{eV})$; note loss of P signals. $D$, An enlargement of zone in $A 1$ demarcated by broken lines, which shows that ribosomal P signals are in direct contact with fragmentary matrix components. $E$, An enlargement of the zone demarcated in $A 2$, which also shows that ribosomal $\mathrm{P}$ signals are generally coapted or in close contact with either laminar or fragmentary matrix components within interlaminar spaces. Scale bars: $A, 0.72 \mu \mathrm{m}$ (primary magnification, $13,800 \times$ ); $B, C, 0.44 \mu \mathrm{m}$ (primary magnification, 22,500×);D, $0.38 \mu \mathrm{m}$ (primary magnification, 13,800×);E, $0.27 \mu \mathrm{m}$ (primary magnification, 13,800×). 


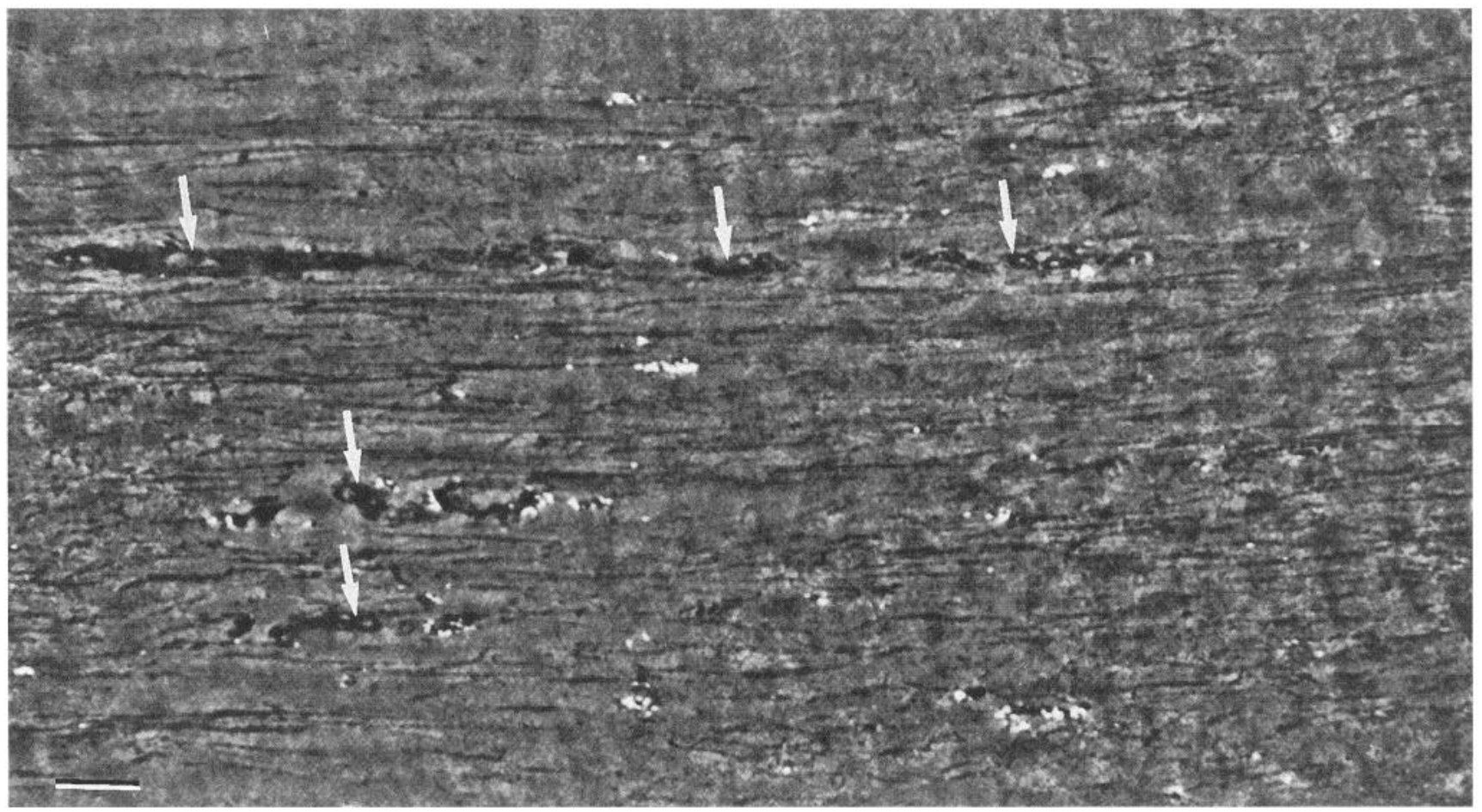

Figure 10. En face view of protruding portions of a periaxoplasmic plaque at the cortical-subcortical interface of axoplasm, as mapped by ESI $(\Delta E=$ $150 \mathrm{eV}$ ) in isolated axoplasm. Exposed matrix structures (arrows) show fenestrations. Many polyribosomal P signals are in close contact with fenestrated and fragmentary matrix (not marked). The ESI micrograph was subjected to computer-based image processing to reduce spatial nonuniformities in background density. Scale bar, $0.44 \mu \mathrm{m}$ (primary magnification, $13,800 \times$ ).

\section{LM level (en face view)}

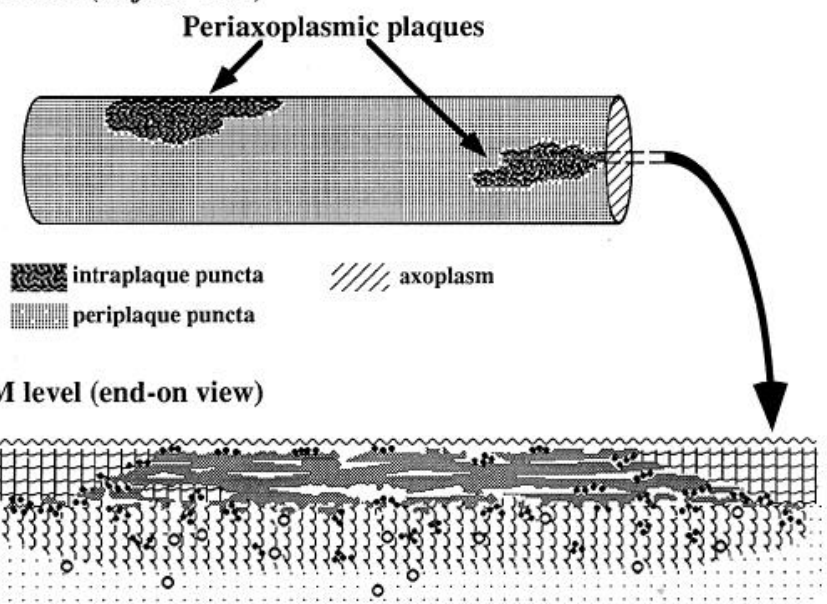

plasmalemma
plaque matrix
$\ldots$ ribosomes

证化 cortical F-actin layer

$\{\{\{\{$ axoplasmic F-actin

neurofilaments

Figure 11. A diagram depicting a simple model of a periaxoplasmic plaque domain. At the LM level, plaques are shown as discrete planar structures at the axoplasmic surface. They are composed of RNase-sensitive fluorescent puncta, as revealed after staining with YOYO-1, which may be fluorescent correlates of polysomes. Although not depicted, fluorescent puncta, often visible in portions of the perimeter of the plaque depending on perspective, are also distributed within a delimited volume of underlying axoplasm, approximately confluent with the plaque. At an EM level, the end-on aspect of the plaque domain has been rotated $90^{\circ}$. Polyribosomes are associated with laminar/fenestrated or fragmentary planar matrix structures and distributed within a volume of contiguous underlying axoplasm. The plaque matrix lies within the cortical F-actin layer adjacent to the plasmalemma, and is presumed to be spatially integrated with axoplasmic polyribosomes through an F-actin cytoskeleton.

zone in the cortex of the axon, consisting of polyribosomes associated with an uncharacterized cortical structural matrix and subcortical axoplasm. The cortical F-actin layer, in conjunction with a subcortical actin network, spatially delimits and integrates the domain. One possible role that the plaque matrix may play is that of a docking site for transported RNA components targeted to these local domains.

The present findings suggest that the metabolic complexity of the axonal compartment of principal neurons is much greater than that implied by prevailing views. It is likely that periaxoplasmic domains are local centers of translational activity, which can account for protein synthesis in the M-cell axon (Edström, 1966; Edström and Sjöstrand, 1969; Alvarez and Benech, 1983; Koenig, 1991). If polypeptides synthesized locally are members of slowtransport groups, as labeling patterns suggest (Koenig, 1991), then present models of how the steady-state mass of axoplasm is regulated may need to be modified.

\section{REFERENCES}

Aggeler J, Seely K (1990) Cytoskeletal dynamics in rabbit synovial fibroblasts. I. Effects of acrylamide on intermediate filaments and microfilaments. Cell Motil Cytoskeleton 16:110-120.

Alvarez J, Benech CR (1983) Axoplasmic incorporation of amino acids in myelinated fiber exceeds that of its soma: a radioautographic study. Exp Neurol 82:25-42.

Alvarez J, Torres C (1985) Slow axoplasmic transport: a fiction? J Theor Biol 112:627-651.

Becker B, Clapper J, Harkins KR, Olson JA (1994) In situ screening assay for cell viability using a dimeric cyanine nucleic acid stain. Anal Biochem 221:78-84.

Black MM, Lasek RJ (1977) The presence of transfer RNA in the axoplasm of the squid giant axon. J Neurobiol 8:229-237.

Bray D, White JG (1988) Cortical flow in animal cells. Science 239:883-888.

Cheney RE, Mooseker MS (1992) Unconventional myosins. Curr Opin Cell Biol 4:27-35. 
Chun JT, Gioio AE, Crispino M, Giuditta A, Kaplan BB (1995) Neurochem Res 20:923-930.

Edmonds BT (1993) ABP50: an actin-binding elongation factor $1 \alpha$ from Dictyostelium discoideum. J Cell Biochem 52:134-139.

Edmonds BT, Murray J, Condeelis J (1995) pH Regulation of the F-actin binding properties of Dictyostelium elongation factor $1 \alpha$. J Biol Chem 270:15222-15230.

Edström A (1966) Amino acid incorporation in isolated Mauthner nerve fibre components. J Neurochem 13:315-321.

Edström A, Sjöstrand J (1969) Protein synthesis in the isolated Mauthner nerve fibre of goldfish. J Neurochem 16:67-81.

Edström A, Edström J-E, Hökfelt T (1969) Sedimentation analysis of ribonucleic acid extracted from isolated Mauthner nerve fibre components. J Neurochem 16:53-66.

Gainer H, Tasaki J, Lasek RJ (1977) Evidence for the glia-neuron protein transfer hypothesis from intracellular profusion studies of squid giant axons. J Cell Biol 74:524-530.

Giorio AE, Chun JT, Crispino M, Perrone Capano C, Giuditta A, Kaplan BB (1994) Kinesin mRNA is present in the squid giant axon. J Neurochem $63: 13-18$.

Giuditta A, Cupello A, Lazzarini G (1980) Ribosomal RNA in the axoplasm of the squid giant axon. J Neurochem 34:1757-1760.

Giuditta A, Hunt T, Santella L (1986) Messenger RNA in squid axoplasm. Neurochem Int 8:435-442.

Giuditta A, Menichini E, Perrone Capano C, Langella M, Martin R, Castigli E, Kaplan BB (1991) Active polysomes in the axoplasm of the squid giant axon. J Neurosci Res 28:18-28.

Giuditta A, Metafora S, Felsani A, Del Rio A (1977) Factors for protein synthesis in the axoplasm of giant squid axons. J Neurochem 28:1393-1395.

Glazer A, Rye HS (1992) Stable dye-DNA intercalation complexes as reagents for high-sensitivity fluorescence detection. Nature 359:859-861.

Hesketh JE, Pryme IF (1991) Interaction between mRNA, ribosomes and the cytoskeleton. Biochem J 277:1-10.

Hirukawa N (1982) The crosslinker systen between neurofilaments, microtubules and membranous organelles revealed by quick freeze, freeze-fracture, deep etching method. J Cell Biol 94:129-142.

Hottman PN, Lasek RJ (1975) 'I'he slow component of axonal transport: identification of major structural polypeptides of the axon and their generality among mammalian neurons. J Cell Biol 66:351-366.

Hoock TC, Newcomb PM, Herman IM (1991) $\beta$-Actin and its mRNA are localized at the plasma membrane and the regions of moving cytoplasm during the cellular response to injury. I Cell Biol 112:653-664.

Howe JG, Hershey JWB (1984) Translation initiation factor and ribosome association with the cytoskeletal framework fraction from HeLa cells. Cell 37:85 93.

Ingoglia NA, Giuditta A, Zanakis MF, Babigian A, Tasaki I, Chakraborty $\mathrm{G}$, Sturman J (1983) Incorporation of $\left[{ }^{3} \mathrm{H}\right]$ amino acids into proteins in a partially purified fraction of axoplasin: evidence for transfer RNAmediated, post-translational protein modification in squid giant axon. J Neurosci 3:2463-2473.

Jeffery WR (1982) Messenger RNA in the cytoskeletal framework: analysis by in situ hybridization. J Cell Biol 95:1-7.

Kaplan BB, Gioio AE, Perrone Capano C, Crispino M, Giuditta A (1992) $\beta$-Actin and $\beta$-tubulin are components of a heterogeneous mRNA population present in the squid giant axon. Mol Cell Neurosci 3:133-144.

Koenig F. (1979) Rihosomal RNA in Manthner axon: implications for a protein synthesizing machinery in the myelinated axon. Brain Res 175:95-107.

Koenig E (1984) Local synthesis of axonal protein. In: Handbook of neurochemistry, Vol 7 (Lajtha A, ed), pp 315-340. New York: Plenum.

Koenig E (1986) Isolation of Mauthner cell axoplasm and an analysis of organelle movement in non-aqueous and aqueous media. Brain Res 398:288-297.

Koenig E (1989) Cycloheximide-sensitive $\left[{ }^{35}\right.$ S $]$ methionine labeling of proteins in goldfish retinal ganglion cell axons in vitro. Brain Res 481:119-123.

Koenig E (1991) Evaluation of local synthesis of axonal proteins in the goldfish Mauthner cell axon and axons of dorsal and ventral roots of the rat in vitro. Mol Cell Neurosci 2:384-394.

Koenig E, Adams P (1982) Local protein synthesizing activity in axonal fields regenerating in vitro. J Neurochem 39:386-400.

Koenig E, Repasky EA (1985) A regional analysis of $\alpha$-spectrin in the isolated Mauthner neuron and in isolated axons of the goldfish and rabbit. J Neurosci 5:705-714.
Korn AP, Spitnik-Elson P, Elson D (1983) Specific visualization of ribosomal RNA in intact ribosomes by electron spectroscopic imaging. Eur J Cell Biol 31:334-340.

Lasek RJ, Hoffman PN (1976) The neuronal cytoskeleton, axonal transport and axonal growth. In: Cell motility: microtubules and related proteins (Goldman R, Pollard T, Rosenbaum J, eds), pr 1021-1049. Cold Spring Harbor, NY: Cold Spring Harbor Laboratory.

Lasek RJ, Dabrowski C, Nordlander R (1973) Analysis of axoplasmic RNA from invertebrate giant axons. Nature New Biol 244:162-165.

Lasek RJ, Gainer H, Barker JL (1977) Cell-to-cell transfer of glial proteins to the squid giant axon. J Cell Biol 74:501-523.

Lasek RJ, Gainer H, Przybylski RJ (1974) Transfer of newly synthesized proteins from Schwann cells to the squid giant axon. Proc Natl Acad Sci USA 71:1188-1192.

Lebeux YJ, Willemot J (1975) An ultrastructural study of microfilaments in rat brain by means of heavy meromyosin labeling. Cell Tissue Res 160:1-36.

Lenk R, Ransom L, Kaufmann Y, Penman S (1977) A cytoskeletal structure with associated polyribosomes obtained from HeLa cells. Cell 10:67-78.

Martin R, Door R, Breitag D (1993) High-resolution imaging of protein phosphorylation in squid axons and synapse by electron energy loss spectroscopy. J Histochem Cytochem 41:1133-1139.

Martin R, Fritz W, Giuditta A (1989) Visualization of polyribosomes in the postsynaptic area of the squid giant synapse by electron spectroscopic imaging. J Neurocytol 18:11-18.

Mohr E, Richter D (1992) Diversity of mRNAs in the axonal compartment of peptidergic neurons in the rat. Eur $J$ Neurosci 4:870 -876.

Nixon RA (1980) Protein degradation in the mouse visual system. I. Degradation of axonally transported and retinal proteins. Brain Res 200:69-83.

Ornelles DA, Fey EG, Penman S (1986) Cytochalasin releases mRNA from the cytoskeletal framework and inhihits protein synthesis. Mol Cell Biol 6:1650-1662.

Ottensmeyer FP (1986) Elemental mapping by energy filtration: advantages, limitations and compromises. Ann NY Acad Sci 483:339-353.

Ottensmeyer FP, Andrew JP (1980) High resolution microanalysis of biological specimens by electron energy loss spectroscopic imaging. J Ultrastruct Res 72:365-376.

Perrone Capano C, Giuditta A, Castigli E, Kaplan BB (1987) Occurrence and sequence complexity of polyadenylated RNA in squid axoplasm. J Neurochem 49:698-704.

Peters A, Palay SL, Webster HF (1970) The fine structure of the nervous system. New York: Harper \& Row.

Ramaekers FCS, Benedetti EL, Dunia I, Vorstenbosch P, Bloemendal H (1983) Polysomes associated with microfilaments in cultured lens cells. Biochem Biophys Acta 740:441-448.

Ryazanov AG, Rudkin BB, Spirin AS (1991) Regulation of protein synthesis at the elongation stage. FEBS Lett 285:170-175.

Rye HS, Dabora JM, Quesada MA, Mathies RA, Glazer AN (1993) Fluorometric assay using dimeric dyes for double- and single-stranded DNA and RNA with picogram sensitivity. Anal Biochem 198:138-142.

Shestakova EA, Motuz LP, Minin AA, Garvrilova LP (1993) Study of localization of the protein-synthesizing machinery along actin filament bundlcs. Ccll Biol Int 17:409-416.

Singer RH, Langevin GL, Lawrence JB (1989) Ultrastructural visualization of cytoskeletal mRNAs and their associated proteins using doublelabel in situ hybridization. J Cell Biol 108:2343-2353.

Stossel TP (1993) On the crawling of animals cells. Science 260:1086-1094.

Taneja KL, Lifshitz LM, Fay FS, Singer RTH (1992) Poly(A) RNA codistribution with microfilaments: evaluation by in situ hybridization and quantitative digital imaging microscopy. J Cell Biol 119:1245-1260.

Tobias GS, Koenig E (1975) Axonal protein synthesizing activity during the early outgrowth period following neurotomy. Exp Neurol 49:221-234.

Tytell M, Lasek RJ (1984) Glial polypeptides transferred into the squid giant axoII. Brain Res 324:223-232.

van Minnen J (1994) RNA in the axonal domain: a new dimension in neuronal functioning? Histochem J 26:377-391.

Willard M, Cowan WM, Vagelos PR (1974) The polypeptide composition of intraaxonally transported proteins: evidence for four transport velocities. Proc Natl Acad Sci USA 71:2183-2187.

Yang W, Demma M, Warren V, Dharmawardhane S, Condeelis J (1990) Identification of an actin-binding protein from Dictyostelium as elongation factor $1 \alpha$. Nature 347:494 496 . 